SECTION 4. Computer science, computer engineering and automation.

\author{
Aibek Amanzholovich Aldabergenov \\ Bachelor of Science in Computer and Information Technology \\ Purdue University, USA \\ aaldaber@purdue.edu
}

\title{
IS SOFTWARE PIRACY PREVENTABLE?
}

\begin{abstract}
One of the biggest problems for large software companies nowadays is the general population's ability to easily obtain paid software illegally on the Internet. Large corporations lose huge amounts of money as a result of increasing software piracy rates. Most of the people don't think of software piracy as a serious crime, but that is one of the main reasons why people keep getting software illegally from the Internet.
\end{abstract}

Key words: software piracy, illegal software, peer-to-peer, software download.

Nowadays, in an era of developed technologies and affordable prices for electronics it is easier than ever to communicate with other people or to read the latest news. Without any doubt, the Internet is a virtual space of meeting, communicating and making friends. On one hand, the Internet has become a place for communication and a source of information on any topic of interest. But on the other hand, the Internet is a place where the theft of digital content and the illegal usage of copyrighted content are enforced. These problems have become more serious after the development of high-speed Internet connections and the launch of P2P (peer-to-peer) networks. The biggest problem for audio-video companies and game and software creators is the piracy of digital content. Many sites provide links for free downloads of music, movies, games and software from servers like Rapidshare. But software creators suffer most from the consequences of sharing software illegally. In the USA, almost every house has a computer connected to the Internet these days. And it has become easier to download software that is pirated and illegally distributed on P2P networks. Also, sharing software with friends and installing software on more computers than allowed by a license are acts of pirate behavior. According to Business Software Alliance (BSA), total losses from software piracy worldwide were $\$ 53$ billion in 2008 (BSA, 2009). And the United States, where the most software companies are located, suffers most from the software piracy. In 2008, the losses from illegally distributed software were equal to $\$ 9.1$ billion only in the United States (BSA, 2009). The amount of money lost when thousands of users worldwide download the software they need is impressive, isn't it? Mostly people download pirated software because of high prices set by companies. For instance, Microsoft Home and Student Office 2007 edition costs 150 dollars, which is a lot of money for a student who has to pay for a dorm, tuition and meals. And when a student needs a word processor to write his assignments, but cannot afford buying a legal copy, he just goes to thepiratebay.org (one of the biggest torrent trackers that contains only pirated digital content), and downloads the software he needs with the latest updates. Seems like it is the best solution for a student. In fact, this action is equal to stealing 150 dollars from Microsoft Corporation, therefore considered as a crime. People don't think of downloading pirated software as a crime because in their opinion, they don't harm anyone and there's no victim. But people don't even imagine that big companies like Microsoft Corporation lose huge amounts of money every year because of the illegal distribution of software. Still, the piracy rate worldwide is high, and it seems impossible to solve this serious problem. However, some technological and legal arrangements can be made in order to decrease the software piracy rate.

One of the main reasons why people use pirated software is the cost of the product. The idea of downloading software for free seems better than buying it. Hood (2005) wrote in his article, how Zhang, a Chinese student, could install an operating system to his computer for free. 
He could download the pirated copy from a server of Tsinghua University, take a licensed version from his friends who work in different organizations to burn a copy, or visit an electronic market to upgrade his computer for couple of dollars (Hood, 2005). The reason that makes this student use copyrighted software illegally is the cost of that software set by Microsoft Corporation. And the higher the cost and the popularity of the software, the more people want to pirate it. For example, the new version of Adobe Photoshop costs 600 dollars. This is one of the most popular and the most used applications. Googling the name of the application will show about 3 million results with links for downloading it for free. China is in the list of twenty five countries with highest piracy rates (BSA, 2009). According to World Development Indicators (WDI), the population of China is 1,330,044,605, and the number of Internet users is equal to 291,640,796 people. So, if we assume that only $1 \%$ of Internet users in China use Photoshop illegally, we can calculate that more than 1.6 billion dollars are lost by Adobe Company with each new release of Photoshop. As Zhang says, software produced by Microsoft Corporation is not affordable because of the prices (Hood, 2005).

The second main reason for pirating software is the accessibility. Before the broadband access to the Internet entered our everyday life, the distribution of pirated software was possible only by using CDs and DVDs. But the development of high-speed Internet gave new opportunities for pirated-software-lovers, and made it possible to download one CD (700 MB) just in few hours (Holsapple, Iyengar, Jin, Rao, 2008). P2P networks are popular among people who need some kinds of software, but don't prefer buying it. And the most used type of P2P networks is Bit Torrent trackers. The work of Bit Torrent trackers is based on a system that allows every single computer to function as a content provider (Hwang \& Lou, 2009). More and more Internet users started using Bit Torrent trackers for downloading the latest releases of movies, software and music.

Many people think that downloading software illegally and burning a copy of licensed software for sharing with friends are not considered as a crime. In people's minds the word "crime" is mostly related with actions like theft, murders and assaults. The person who stole some amount of money from someone would be called a thief or a criminal, but the person who used or distributed software for free is rarely called a criminal. The widespread idea among people that using copyrighted software for free is permissible makes it more difficult for legal agencies and software creators to convince people that this action is wrong (Holsapple, Iyengar, Jin, Rao, 2008).

In fact, software piracy is a serious crime. And this problem has become more actual as the number of Internet users has increased rapidly in last several years. Criminologists argue that the piracy behavior falls into a category of bad behavior, in other words, criminal behavior (Holsapple, Iyengar, Jin, Rao, 2008).

A person who pirated software can be sentenced to minimum of five and maximum of ten years in prison (Burnett, Craig, Honick, 2005). The story of a young person named Sabuj Pattanayek, who is 21 , is a proof that the consequences of pirate behavior are more serious than people may think. Sabuj Pattanayek was sentenced to 41 months in prison for being a member of a group that specialized on pirating software (Burnett, Craig, Honick, 2005). A young student at Duke University suddenly became a convicted person. And the worst thing is that he will have a criminal record after he is released from jail, and chances of finding a good job will be minimal.

The United States is one of the countries where the software piracy rates are the lowest, but the losses from piracy are the highest (BSA, 2009). One of the biggest companies in software industry, Microsoft Corporation, earns $\$ 175$ billion from sells, and looses about 36 percent of its business because of piracy (Emerson, Ernsberger, Stryker, 2001). Many researchers in the field of Computer Science are looking for solutions that could decrease the piracy rates.

Technological solutions like watermarking, tagging and encryption can be used to decrease the software piracy rates. These methods use the algorithms that are integrated into applications to make the process of copying more difficult for pirates. The use of these methods 
allows installing the software only for license owners. But some researchers argue that hackers and code breakers are more interested in pirating the software which has more complicated protection system (Holsapple, Iyengar, Jin, Rao, 2008). For example, the product of the giant software company that has the most advanced technologies, Microsoft Windows, usually appears on P2P networks one or two weeks after its release with installation instructions. Another method called content poisoning can be used to prevent illegal sharing of software over P2P networks. The content poisoning method uses the server of the P2P network to identify pirates, and sends poisoned or incorrect file pieces to violators, thus increasing the download time or making the downloading of files impossible. But this method is effective only for certain types of P2P networks (Hwang \& Lou, 2009). Some popular Bit Torrent trackers like thepiratebay.org are resistant to content poisoning. Also, it is impossible to identify the violators in these trackers because thousands of people downloading software from each others can be considered as pirates (Hwang \& Lou, 2009).

Although it seems very difficult to decrease the software piracy rate using technological solutions, other arrangements like making the legal sanctions stricter to deter piracy or setting lower prices for software could decrease the usage of illegitimate software. People would think twice before downloading or distributing illegitimate software if the penalty for pirating software was 10 years in prison and a fine of $\$ 500,000$. Lowering the prices of software would decrease the software piracy rates in countries where the prices set by American companies are inappropriate for the market. But unless people are convinced that using software illegally is a crime and results in losses of billions of dollars each year, P2P networks will continue to function and people will still share software with others. Unless the notion that software piracy is a deviant, rule-breaking behavior is accepted by the society, software pirates will never be called criminals. It is unlikely that software piracy will decrease if only laws are made stricter or costs are lowered, but the combination of the arrangements mentioned above will result in great declines in software piracy rates.

\section{References}

1. BSA.org: Sixth Annual BSA and IDC Global Software Piracy Study. (2009). Retrieved November 25, 2009, from http://global.bsa.org/globalpiracy2008/studies/globalpiracy2008.pdf

2. Burnett, M., Craig, P., Honick, R. (2005). Software Piracy Exposed. Rockland: Syngress Publishing, Inc.

3. Caborn, A. (1997). Are you a software thief, but don't know it. Management Today. Retrieved November 26, 2013, from http://www.managementtoday.co.uk/search/article/410979/uk-software-thief-dont-knowit/

4. Emerson, T., Ernsberger, R., Stryker, M. (2001, October 29). Software Pirates, Beware. Newsweek, 138, 68. Retrieved November 18, 2013, from Academic Search Premier database.

5. Holsapple, C.W., Iyengar, D., Jin, H., Rao, S. (2008). Parameters for Software Piracy Research. Information Society, 24(4), 199-218. Retrieved November 17, 2009, from Academic Search Premier database.

6. Hood, M. (2005). Steal This Software. IEEE Spectrum, 42(6), 52-53. Retrieved November 20, 2009, from Academic Search Premier database.

7. Hwang, K., Lou, X. (2009). Collusive Piracy Prevention in P2P Content Delivery Networks. IEEE Transactions on Computers, 58(7), 970-983. Retrieved November 18, 2009, from Academic Search Premier database. 
8. Husted B. (2000). The impact of national culture on software piracy. Journal of Business Ethics. 26(3), 197-211. Retrieved October 3, 2013, from Academic Search Premier database.

9. Moores, T., G. Dhillon. (2000). Software piracy: A view from Hong Kong. Communications of the ACM. 43(12), 88-93.

10. Swinyard, W., H. Rinne, and A. K. Kau. (1990). The morality of software piracy: A cross cultural analysis. Journal of Business Ethics. 9(8), 655-664. Retrieved November 15, 2009, from Academic Search Premier database. 